\title{
La retirada del Reino Unido de la UE, un viaje hacia ninguna parte
}

\section{The Withdrawal of the United Kingdom from fhe EU, a Journey to Nowhere}

\author{
Pablo Antonio Fernández Sánchez ${ }^{1}$ \\ Universidad de Sevilla (España)
}

Recibido: 28-09-20

Aceptado: 26-10-20

\section{Resumen}

Las relaciones entre el Reino Unido (RU) y la Unión Europea (UE) siempre han sido tensas. Ya desde la más tierna infancia comunitaria, los británicos pusieron sobre la mesa sus exigencias, de las que luego los polacos y los checos aprendieron tanto. Esto siempre ha debilitado a la UE, lo que también ha debilitado su posición como actor global.

Nada hay qué reprochar a una retirada que se ha hecho con escrupuloso cumplimiento del derecho, aunque, a veces, haya sido un esperpento insoportable.

El impacto del Brexit alcanza prácticamente a todos los temas en los que tiene competencias la UE, que en menor o mayor medida son casi todos los que pueda pensarse en cuanto a la regulación de la vida de las personas y de los Estados. Por ello, hay que estar muy vigilantes para que las consecuencias en

\footnotetext{
${ }^{1}$ (pafernandez@us.es). Catedrático de Derecho Internacional Público y Relaciones Internacionales, y Presidente del Instituto Hispano-Luso-Americano y Filipino de Derecho Internacional. Sus últimos tres libros han sido: El Derecho de los Inmigrantes Irregulares a Tener Derechos, Tirant lo Blanc, Valencia, 2019 (ISBN: 978-84-1313-119-1; Peacekeeping, Global Perspectives, Challenges and Impacts, (Editor), Nova Sciences Publishers, New York, 2018, ISBN: 978-1-53613-431-5; New Approaches to the Law of the Sea (In Honor of Ambassador José Antonio de Yturriaga) (Ed.), Nova Science Publishers, New York, 2017 (ISBN: 978-1-53611-984-8). Y sus tres útimos artículos: "La protección internacional del Derecho a la dignidad", en Pinto Fontanillo, José Antonio \& Sánchez De La Torre, Ángel, Derechos humanos en el Siglo XXI. En la conmemoración del 70 aniversario declaración Los derechos humanos desde la perspectiva jurídica, Tomo IV, Edisofer, Madrid, 2020, (ISBN: 978-84-18493-03-4); "Immigrazione irregolare e diritti umani: la prospettiva della Corte EDU e della Corte UE”, en Freedom, Security \& Justice: European Legal Studies, 2020, n 1, pp. 52-74; "La Declaración de Bogotá y la Articulación Normativa de los Deberes del Ser Humano" en Revista Electrónica Iberoamericana, Edición Especial, 2019, págs. 166-204. (ISSN-e 1988-0618).

ORCID: https://orcid.org/0000-0002-9614-9760.
} 
ambos espacios jurídicos sean los mínimos posibles. Para ello se requiere unas relaciones jurídicas futuras que encajen en esos objetivos.

El control migratorio no le resultará fácil llevarlo a cabo al RU, porque incidirá en sus propios intereses y los desafíos internos y externos de la UE, que son desafíos globales que sólo podremos resolver si somos actores significativos; será más difícil hacerlo sin el RU pero el RU quedará en la irrelevancia política internacional.

Palabras-clave: Brexit, Unión Europea, control migratorio, desafíos globales.

\begin{abstract}
The relationship between the United Kingdom (UK) and the European Union (EU) has always been tense. From the earliest communal childhood, the British put their demands on the table, from which the Poles and Czechs have learned so much. This has always weakened the EU, which has also weakened its position as a global actor.

There is nothing to blame for a withdrawal that has been made with scrupulous compliance with the law, although, at times, it has been an unbearable absurdity.

The impact of Brexit reaches practically all the issues in which the EU has competences, which, to a lesser or greater extent, is almost all that can be thought of in terms of regulating the lives of individuals and States. Therefore, we must be very vigilant so that the consequences in both legal spaces are the minimum possible. This requires future legal relationships that fit those objectives.

Migration control will not be easy for the UK to carry out, because it will affect its own interests and the internal and external challenges of the EU, which are global challenges that we can only solve if we are a significant actor, it will be more difficult to do without the UK but the UK will be left in international political irrelevance.
\end{abstract}

Key-words: Brexit, European Union, Migration Control, Global Challenges.

\title{
Introducción
}

E1 23 de junio de 2016, el Reino Unido celebró un referéndum en relación con la permanencia o salida del Reino Unido de la UE. El resultado, muy ajustado, favoreció la retirada, por lo que el Reino Unido notificó al Consejo Europeo el 29 de marzo de 2017 su voluntad expresa de proceder a la salida de la UE. 
Es la primera vez que se pone en marcha un procedimiento establecido en el art. 50 del Tratado de Lisboa, según el cual un Estado miembro de la UE puede decidir retirarse de la Organización, de forma voluntaria, siguiendo un procedimiento establecido en el art. 218 del Tratado de Funcionamiento de la UE. Esto es a lo que se le ha llamado Brexit, a la retirada del Reino Unido de la UE.

Obviamente, la negociación para adecuar todas las posibles incidencias de las consecuencias de la retirada ha tenido que ser muy minuciosa, porque el grado de integración acumulada alcanzaba casi todos los sectores que podamos imaginar y más de 50.000 normas que ya se ejecutan en el Reino Unido, además de influir en millones, incluso en cientos de millones de personas.

El 25 de noviembre de 2018, en una Reunión Extraordinaria del Consejo Europeo, se decidió refrendar el Acuerdo relativo a la Retirada del Reino Unido de Gran Bretaña e Irlanda del Norte de la Unión Europea y de la Comunidad Europea de la Energía Atómica.

El Consejo adoptaba una propuesta para un tratado internacional entre la UE, la CEEA y el Reino Unido, que tenía que ser aprobado por el Parlamento Europeo y por todos y cada uno de los Estados miembros, según sus propias normas constitucionales, incluyendo al Reino Unido.

Sin embargo, al producirse un cambio de gobierno en el Reino Unido, derivado precisamente del terremoto que provocó el Brexit, se decidió revisar el texto del Acuerdo que aprobó el Consejo Europeo el 17 de octubre de 2017.

El proceso negociador no sería fácil. Por poner un simple ejemplo, España tuvo que protestar (hay que estar muy vigilante en todo) por una extraña maniobra diplomática que provocó una intensa bronca entre los Representantes Permanentes de los Estados ante la UE. No quedaba satisfecha con la situación en la que se establecían las futuras negociaciones entre el Reino Unido y la UE en relación con Gibraltar, porque España reclamaba un derecho de veto sobre las mismas.

Como no fue posible abrir de nuevo el proceso negociador, se optó por una vía, perfectamente legal, que incorporó una Declaración Interpretativa de todos los firmantes del Acuerdo, incluido el Reino Unido. El contenido de dicha Declaración, tanto el Consejo Europeo (firmada por Donald Tusk) como la Comisión (firmada por Jean-Claude Juncker), reconocen que el art. 184 no impone obligaciones en cuanto al alcance territorial, en el sentido de que dichos acuerdos tengan el mismo alcance territorial que el previsto en el Artículo 3 del Acuerdo de Retirada. El texto, procedente de una simple traducción del inglés dice exactamente que una vez que el Reino Unido abandone la Unión, Gibraltar no se incluirá en el ámbito territorial de los acuerdos que se celebrarán entre la Unión y el Reino Unido. Sin embargo, esto no excluye la posibilidad de tener acuerdos separados entre la Unión y el Reino Unido con respecto a 
Gibraltar. Sin perjuicio de las competencias de la Unión y en el pleno respeto de la integridad territorial de sus Estados miembros, según garantiza el artículo 4, apartado 2, del Tratado de la Unión Europea, dichos acuerdos independientes requerirán un acuerdo previo del Reino de España.

Esta Declaración Interpretativa coincide con la manifestación escrita del Representante Permanente del Reino Unido ante la UE, Sir Tim Barrow, que es la persona designada formalmente por el RU para comprometer la voluntad jurídica del Estado en estas cuestiones. Por tanto, se trata de una Declaración Interpretativa común entre todas las Partes sobre un artículo del Acuerdo que se encontrará en el texto normativo una vez que esté formalmente en vigor. Esto queda recogido en la propia Declaración del Consejo Europeo y de la Comisión, donde señalan que el Consejo Europeo y la Comisión Europea toman nota de la Declaración del Reino Unido de que el Reino Unido comparte esta interpretación. Es decir, España seguirá manteniendo el control en el proceso de decisión y, además, en el futuro lo seguirá teniendo aún más.

Todas estas cuestiones relacionadas con las relaciones históricas entre el Reino Unido y la UE, las causas y consecuencias de la solicitud de retirada, el procedimiento y el marco de las futuras relaciones son tenidos en cuenta como parte del proceso para el punto clave de esta reflexión.

Aparte de las cuestiones puntuales de cada Estado miembro, de las necesidades del Reino Unido o de la solución de los temas que afectan a las personas, es muy importante preguntarse si la retirada del Reino Unido de la UE supone una herida de muerte para la UE o una amputación del cuerpo principal de la UE. También cabría preguntarse por la supervivencia de la UE sin uno de sus elementos esenciales en el devenir de la historia europea.

Las respuestas pueden ser múltiples y dependerán del enfoque metodológico. Yo me voy a esforzar en hacer un análisis desde el punto de vista más general de la pervivencia de una UE en el contexto global de un mundo multipolar, descentralizado, desarticulado, descontrolado, donde los valores europeos deberían estar en el centro de todas las discusiones, no por eurocentrismo sino porque han demostrado a lo largo de la historia que son los únicos capaces de converger en el humanismo igualitarista donde el ser humano es la medida de todas las cosas.

\section{La difícil relación histórica entre el Reino Unido y la Unión Europea}

En los años cincuenta, el Reino Unido había declinado participar en las Comunidades Europeas ${ }^{2}$, en la creencia de que sus relaciones con la

${ }^{2}$ Bar Cendón, Antonio, "El Reino Unido y la Unión Europea: Inicio y Fin de una Relación Atormentada", en Teoría y Realidad Constitucional, n 4, 2017, p. 144.

Araucaria. Revista Iberoamericana de Filosofia, Politica, Humanidades y Relaciones Internacionales, año $22, \mathrm{n}^{\circ} 45$. Tercer cuatrimestre de 2020. Pp. 549-573. ISSN 1575-6823 e-ISSN 2340-2199 https://dx.doi.org/10.12795/araucaria.2020.i45.23 
Commonwealth y con los Estados Unidos le daban una posición suficientemente segura en el ámbito internacional. Pronto percibió que no era así y, ante el éxito comunitario, propuso crear la Asociación Europea de Libre Comercio (EFTA) ${ }^{3}$.

La EFTA proporcionaba un marco suficiente para el librecambio, que permitía una política proteccionista de los Estados con la única necesidad de suprimir los aranceles y contingentes internos. Sin embargo, empezó a resultar insuficiente para Reino Unido. A los británicos les interesaba cada vez más la CEE desde un punto de vista económico, pero a su vez tenía grandes condicionantes entre los que destacan sus reticencias a la Política Agrícola Común y la necesidad de dar un tratamiento preferente a sus antiguas colonias y a los países de la Commonwealth.

La CEE ganaba en prestigio y en bienestar económico mientras que el Reino Unido se estancaba. Por ello, el 9 de agosto de 1961, Reino Unido presentaría su solicitud de ingreso en las CCEE, junto a Irlanda, Dinamarca y Noruega. Reino Unido contó con la oposición de la Francia de De Gaulle, para su ingreso ${ }^{4}$. En 1967 volvió a presentar su solicitud, que también fue denegada ${ }^{5}$. Tras la caída de De Gaulle, en 1969, el Reino Unido volvió a solicitar, por tercera vez, su ingreso en las Comunidades Europeas.

Ahora había otro panorama político y, sin necesidad de referéndum en el Reino Unido,

El resultado del debate y la decisión de los Comunes fueron claramente favorables a la adhesión a las CCEE: votaron a favor 356 diputados (54.8\%), y 244 lo hicieron en contra (37.5\%). De esta manera, el 31 de diciembre de 1972 el RU abandonó la EFTA y el 1 de enero de 1973 ingresó en las CCEE6 .

Después de duras negociaciones, se firmó en 1972 el Tratado de Adhesión de las Comunidades Europeas con el Reino Unido. Este instrumento internacional entró en vigor en 1973. Desde entonces comenzó todo un período de ajuste que hizo a las Comunidades avanzar más lentamente. Sólo dos años más tarde de la ampliación, el Reino Unido exigió renegociar su adhesión y obtuvo ciertas mejoras en cuanto a su participación presupuestaria y a los productos

${ }^{3}$ Una excelente monografía, muy actualizada, sobre esta Organización Internacional, incluyendo su historia y su actual relación con el Espacio Económico Europeo (EEE), puede verse en Baur, George, Sánchez Rydelski, Michael \& Zatschler, Carsten, European Free Trade Association (EFTA) and the European Economic Area (EEA), second edition, Kluwer Law International, The Netherlands, 2018.

4 De Gaulle, Charles, "Conférence de presse du 14 janvier 1963 (sur l'entrée de la GrandeBretagne dans la CEE)", en De Gaulle, Charles, Paroles Publiques (Institut national de l'audiovisuel, INA, Réf. 00085: http:// fresques.ina.fr/de-gaulle/fiche-media/Gaulle00085/conference-de-presse-du14-janvier-1963-sur-l-entree-de-la-grande-bretagne-dans-la-cee.html.

5 De Gaulle, Charles, "Conférence de presse de Charles de Gaulle: le second veto (27 novembre 1967)", Centre Virtuel de la Connaissance sur l'Europe (CVCE), Université du Luxembourg: http:// www.cvce.eu.

${ }^{6}$ Bar Cendón, Antonio, "El Reino Unido y la Unión Europea... op. cit., p. 148. 
lácteos procedentes de Nueva Zelanda. El Consejo Europeo de Dublín de los días 10 y 11 de marzo de 1975 decidió asumir las reivindicaciones de Londres en cuanto a una corrección presupuestaria que alcanzaría los 125 millones de libras esterlinas, constituyendo el primer "cheque británico" de la historia de las relaciones entre el Reino Unido y la UE.

Sin embargo, el problema económico no parecía que fuera el gran escollo. En palabras del Prof. Bar Cendón, "el nacionalismo, el orgullo nacional, nunca fue un problema a superar en el RU, muy al contrario, es la verdadera espina dorsal del ser británico, y de aquí que la relación del RU con los Seis primero y con la Unión Europea después, se basase siempre en el recelo, en el temor a perder su identidad nacional y su condición de Estado soberano. En este sentido, el RU nunca quiso jugar el papel de líder político de la Unión y de competir en ello con Francia y Alemania; muy al contrario, el RU se ha limitado siempre a operar como un freno, como un contrapeso que ha tratado de limitar siempre la velocidad y reducir la intensidad del proceso de la integración europea"

En 1979, planteó una nueva renegociación, con la que consiguió ventajas financieras, agrícolas y pesqueras.

En 1984 consiguió lo que ya se conocía como el "cheque británico", es decir el retorno de dos tercios del déficit fiscal del Reino Unido en el bloque europeo (ello era porque Reino Unido no se beneficiaba de la PAC que en aquellos momentos suponían dos tercios del presupuesto comunitario y porque la contribución británica al presupuesto comunitario era mayor que lo que significaba su PIB en el conjunto de las CCEE) $)^{8}$.

A pesar de ello y otras muchas singularidades de las que se ha beneficiado, como el famoso opting out, en la cultura política y ciudadana británica ha habido un deseo expreso de excluirse del marco de la Unión Europea9.

Desde el Tratado de Maastricht, donde ya se autoexcluyó de la política social europea a través del Protocolo sobre Política Social, que se cancelaría por la aprobación por Tony Blair del Tratado de Ámsterdam, que sí incluyó la política social europea ${ }^{10}$, el Reino Unido ha venido ejerciendo una política consentida por la UE: el opting out.

El Reino Unido no participa en la Unión Económica y Monetaria (por tanto, tampoco en la gobernanza de la eurozona, que incluye el Eurogrupo, el Mecanismo Europeo de Estabilidad, el Pacto de Estabilidad y Crecimiento, la regulación jurídica del sector financiero y en las relaciones internacionales relacionadas con todos estos temas) ${ }^{11}$.

\footnotetext{
${ }^{7}$ Ibidem, p. 150.

${ }^{8}$ Calvo Hornero, Antonia, Organización Monetaria y Financiera de la Unión Europea, segunda edición, Editorial Universitaria Ramón Areces, UNED, Madrid, 219, p. 221.

9 Adler-Nissen, Rebecca, Opting Out of the European Union, Diplomacy, Sovereignty and European Integration, Cambridge University Press, Cambrigde, UK, 2014.

${ }^{10}$ Alonso Seco, José María, Política Social Europea, UNED, Madrid, 2014, cap. 4.1.

11 López Escudero, Manuel, "la Unión Económica y Monetaria (I)", en Ortega Gómez, Marta
} 
Tampoco participa en Schengen, lo que le permite ejercer controles en sus fronteras, incluso de los propios ciudadanos europeos y excluirse de numerosas normas del espacio de seguridad, libertad y justicia ${ }^{12}$.

Igualmente se autoexcluyó, en este caso junto con un compañero de viaje como Polonia, para evitar la aplicación completa de la Carta de Derechos Fundamentales de la UE, en la medida que contenga derechos no contemplados en su legislación interna (Protocolo 30 del Tratado de Lisboa) ${ }^{13}$.

\section{La retirada del Reino Unido, entre el derecho y el esperpento}

Durante los últimos años hemos estado viviendo idas y venidas en relación con el Brexit que no han sido muy bien comprendidas por los ciudadanos. Ello se debe al escrupuloso cumplimiento del procedimiento jurídico exigido, pero también a una escenografía político-diplomática que ha rayado el esperpento. Por ello, se requiere poner orden para comprender la situación desde la crítica.

Nada que decir, en el marco del Derecho Internacional, cuando un Estado desea retirarse del marco obligacional que suponen los tratados, siempre que se haga de conformidad con el procedimiento establecido.

La extinción o terminación de los tratados tiene su origen en situaciones sobrevenidas, cuando el tratado conserva aún su validez, o en decisiones de las partes posteriores a su entrada en vigor.

De acuerdo con el art. 56 de la Convención de Viena sobre el Derecho de los Tratados una Parte en un Tratado puede denunciarlo de conformidad con el Tratado, si se regula la retirada. Este es el caso del Brexit.

En efecto, su artículo 50 establece el procedimiento por el que un Estado miembro se puede retirar de la Unión Europea. Es decir, tiene previsto la retirada del Estado miembro de la UE que lo solicite.

Era la primera vez que aparecía una disposición semejante, lo que había hecho creer a muchos juristas, poco expertos en Derecho Internacional, que la UE era una organización supranacional y no internacional por su carácter irreversible o irrevocable. Pues bien, aquí tenemos un ejemplo de

(Ed.), Las Politicas de la Unión Europea en el Siglo XXI, Bosch Editor, Barcelona, 2017, pp. 299-338, especialmente el epígrafe sobre "La posición jurídica de los países de la UE que no han adoptado el euro", pp. 304-306.

12 Emerson, Michael, "Britain, Ireland and Schengen: Time for Smarter Bargain on Visas", en Center for European Policy Studies Policy Briefs, $\mathrm{n}^{\circ}$ 249, 2011.

${ }_{13}$ Beale, Kieron, "The United Kingdom without the Charter of Fundamental Rights of the European Union: Putting Down the Dog that thid not Bark", en Birkinshaw, Patrick J. \& Biondi, Andrea (Eds.), Brtain Alone! - The implications and Consequences of United Kingdom Exit from the EU, Walter Kluwer, The Netherlands, 2018, cap. 14. 
que, como decía el Tribunal Supremo alemán, los Estados Miembros son los "señores de los Tratados" (Herren der Verträge) ${ }^{14}$.

Por tanto, el TUE hace expresa mención a esta posibilidad de revocabilidad de la pertenencia de un Estado a la UE ${ }^{15}$.

Pues bien, de conformidad con las normas constitucionales del Reino Unido, el 23 de junio de 2016 se produjo un referéndum no vinculante con un resultado favorable a la salida del Reino Unido de la UE (Brexit: acrónimo de Britain y exit). El 29 de marzo de 2017, el Reino Unido comunica formalmente al Presidente del Consejo de la UE su intención de abandonar la Organización ${ }^{16}$, por lo que, de conformidad con el art. 50 del TUE, se iniciaría el período de dos años para establecer un acuerdo de salida y, de no ser factible, el 29 de marzo de 2019 se produciría la salida definitiva, aunque de forma brusca.

De conformidad con el art. $218-3^{\circ}$ del TFUE (según se recoge en el propio art. 50 del TUE), el 27 de julio de 2016, Jean-Claude Juncker, Presidente de la Comisión Europea, nombró Negociador Principal para las negociaciones con el Reino Unido al ex-Comisario de Mercado Interior y Servicios y ex-Ministro francés de Asuntos Exteriores y de Agricultura, Michel Bernier.

La UE inicia el procedimiento de negociación de las condiciones del abandono, en el que el Consejo de la UE adopta Orientaciones para la negociación y establece unos Principios Rectores para la Transparencia de las Negociaciones del Brexit ${ }^{17}$.

${ }^{14}$ BVerfGE 89, 115. Su traducción no oficial en español está en la R.I.E. vol. 3, 1993, págs. $975-$ 1030. Un análisis de la misma puede verse en Torsten, Stein, "La Sentencia del Tribunal Constitucional Alemán sobre el Tratado de Maastricht", R.I.E., vol 21, n³ 3, 1994, pp. 745-770.

${ }^{15}$ Este art. 50 dispone textualmente: "1. Todo Estado miembro podrá decidir, de conformidad con sus normas constitucionales, retirarse de la Unión. 2. El Estado miembro que decida retirarse notificará su intención al Consejo Europeo. A la luz de las orientaciones del Consejo Europeo, la Unión negociará y celebrará con ese Estado un acuerdo que establecerá la forma de su retirada, teniendo en cuenta el marco de sus relaciones futuras con la Unión. Este acuerdo se negociará con arreglo al apartado 3 del artículo 218 del Tratado de Funcionamiento de la Unión Europea. El Consejo lo celebrará en nombre de la Unión por mayoría cualificada, previa aprobación del Parlamento Europeo. 3. Los Tratados dejarán de aplicarse al Estado de que se trate a partir de la fecha de entrada en vigor del acuerdo de retirada o, en su defecto, a los dos años de la notificación a que se refiere el apartado 2, salvo si el Consejo Europeo, de acuerdo con dicho Estado, decide por unanimidad prorrogar dicho plazo. 4. A efectos de los apartados 2 y 3, el miembro del Consejo Europeo y del Consejo que represente al Estado miembro que se retire no participará ni en las deliberaciones ni en las decisiones del Consejo Europeo o del Consejo que le afecten. La mayoría cualificada se definirá de conformidad con la letra b) del apartado 3 del artículo 238 del Tratado de Funcionamiento de la Unión Europea. 5. Si el Estado miembro que se ha retirado de la Unión solicita de nuevo la adhesión, su solicitud se someterá al procedimiento establecido en el artículo 49".

${ }_{16}$ Ver la carta de notificación en http://data.consilium.europa.eu/doc/document/XT-20001-2017INIT/en/pdf

${ }^{17} \mathrm{http} / /$ data.consilium.europa.eu/doc/document/XT-21023-2017-INIT/en/pdf 
El diplomático francés y negociador por parte de la UE, Michael Barnier inicia las duras negociaciones con el Gobierno británico. Empiezan a reubicarse las Agencias de la UE establecidas en el Reino Unido: Agencia Europea del Medicamento y Autoridad Bancaria Europea, que se irán a Ámsterdam (Países Bajos) y París (Francia), respectivamente.

El 25 de noviembre de 2018, el Consejo Europeo adopta el Acuerdo sobre la Retirada del Reino Unido de Gran Bretaña e Irlanda del Norte de la Unión Europea y de la Comunidad Europea de la Energía Atómica, cuyo texto oficial sería publicado en el DOUE de 19 de febrero de $2019^{18}$. El 7 de enero de 2019 se acuerda la Decisión del Consejo relativa a la firma de dicho Acuerdo ${ }^{19}$.

La idea era garantizar una retirada ordenada, proporcionar protección recíproca a los ciudadanos que hayan ejercido su derecho de libre circulación con fecha anterior a la fecha fijada en el Acuerdo, determinar un período transitorio, el establecimiento de una liquidación financiera única, en definitiva, buscar "un equilibrio global de beneficios, derechos y obligaciones para la Unión y el Reino Unido", según se señala en el Preámbulo del citado Acuerdo ${ }^{20}$.

Ahora bien, este Acuerdo, insisto, aceptado por la UE y por el Gobierno del Reino Unido, tenía que pasar por el filtro del Parlamento británico para que pudiera generar efectos jurídicos, dado que en el sistema constitucional británico se requiere este paso para poder depositar el instrumento de ratificación del mismo. Y ese fue uno de los problemas del retraso actual, que el Parlamento británico no aprobaba este Acuerdo.

Simultáneamente a este Acuerdo sobre la retirada del Reino Unido, se había negociado una Declaración Política sobre las Orientaciones Relativas al Marco de la Relación Futura con el Reino Unido (23 de marzo de 2018) ${ }^{21}$. La idea era negociar con el Reino Unido un marco adecuado para establecer una “cooperación económica y comercial, así como en otros ámbitos, en particular la lucha contra el terrorismo y la delincuencia internacional, así como la seguridad, la defensa y la política exterior"22. El límite era clave: "las cuatro libertades son indivisibles y que no se puede escoger «a la carta» mediante una participación por sectores en el mercado único, algo que socavaría la integridad y el correcto funcionamiento de este"23.

Sin embargo, como consecuencia del rechazo por parte del Parlamento británico del Acuerdo de retirada, la Premier Theresa May propuso el 20 de

${ }^{18} \mathrm{https}$ ://eur-lex.europa.eu/legal-content/ES/TXT/PDF/?uri=CELEX:12019W/TXT\&from=ES

19 https://data.consilium.europa.eu/doc/document/XT-21106-2018-INIT/es/pdf

${ }^{20}$ Acuerdo sobre la retirada del Reino Unido de Gran Bretaña e Irlanda del Norte de la Unión Europea y de la Comunidad Europea de la Energía Atómica, DOUE C 384 de 12 de noviembre de 2019 , pp. 1 y ss..

${ }^{21}$ Declaración política en la que se expone el marco de las relaciones futuras entre la Unión Europea y el Reino Unido, DOUE C 384 de 12 de noviembre de 2019, pp. 178 y ss.

${ }^{22} \mathrm{https} / / / \mathrm{www} . c o n s i l i u m . e u r o p a . e u / m e d i a / 33498 / 23$-euco-art50-guidelines-es.pdf, par. 3.

${ }^{23}$ Ibidem, par. 7. 
marzo de 2019 una solicitud de prórroga "hasta el 30 de junio de 2019 del plazo previsto por el artículo 50, conforme al artículo 50, apartado 3, del Tratado de la Unión Europea, en su versión aplicable en el artículo 106 bis del Tratado Euratom"24.

El Consejo Europeo, por el contrario, no acepta esta prórroga. En sus Conclusiones del Consejo Europeo del 21 de marzo de 2019:

El Consejo Europeo aprueba una prórroga hasta el 22 de mayo de 2019, a condición de que la Cámara de los Comunes apruebe el Acuerdo de Retirada la semana próxima. En caso de que la Cámara de los Comunes no apruebe el Acuerdo de Retirada la semana próxima, el Consejo Europeo aprueba una prórroga hasta el 12 de abril de 2019 y confía en que, antes de esa fecha, el Reino Unido indique una forma de proceder para que la estudie el Consejo Europeo $^{25}$.

De esta forma se adopta la Decisión de prórroga del citado Acuerdo el 22 de marzo de $2019^{26}$.

Sin embargo, a mediados de 2019, se produce un cambio de gobierno en el Reino Unido, lo que provoca la necesidad de renegociar el Acuerdo de Retirada. Se acordó un nuevo texto el 17 de octubre de 2019 y el 24 de enero de 2020 se firma el Acuerdo de Retirada entre el Reino Unido y la UE, entrando en vigor el 1 de febrero de 2020. El Reino Unido deja de ser Estado miembro de la UE y comienza su consideración como país tercero.

Con esta entrada en vigor se inicia un período transitorio que debe durar, como máximo, hasta el 31 de diciembre de 2020, período en el que nos encontramos en el momento de escribir estas páginas. Desconocemos cuáles serán las normas por las que se van a regular las relaciones futuras entre ambas partes porque, hasta la fecha, no ha habido acuerdo al respecto. Todas las expectativas están, ahora, en si habrá un Brexit duro o blando. ¿A quién dañará más el Brexit a la Unión Europea o al Reino Unido? ${ }^{27}$.

\section{Los impactos inmediatos de un posible Brexit radical}

Los impactos que va a provocar el Brexit son tan extensos como las materias reguladas por el ordenamiento jurídico de la UE. Habrá que regular y desregular aspectos relacionados con la sanidad, los seguros médicos, el

\footnotetext{
${ }^{24} \mathrm{https}$ //data.consilium.europa.eu/doc/document/XT-20005-2019-INIT/es/pdf

25 https://www.consilium.europa.eu/es/press/press-releases/2019/03/21/european-council-art-50conclusions-21-march-2019/, par. 3

${ }^{26} \mathrm{https}$ //data.consilium.europa.eu/doc/document/XT-20006-2019-INIT/es/pdf

27 Brown, Stuart A., "Brexit, the UK and Europe: Why, how and what next?", en Journal of European Integration, 41:1, 2019, pp.123-129, DOI: 10.1080/07036337.2018.1525660.
} 
empleo, los permisos de circulación y de conducción, exportaciones, cobro de pensiones, pesca, fondos europeos, títulos universitarios y un sinfín de cuestiones. Hay decenas de miles de normas europeas transpuestas en el Reino Unido, que afectan a todos los sectores de la vida de los ciudadanos y que, ahora, la mayoría, deben ser cambiadas por las normas propias.

Hay que tener en cuenta que, "en cualquier caso, dado el reducido tamaño de la economía británica en comparación a la de los restantes 27 , puede anticiparse que el daño será mayor para Reino Unido que para la UE, pero también mayor para España que para otros países de la UE. Asimismo, para los países de la UE es esencial que quede claro que el Reino Unido estará en peor posición desde el punto de vista económico fuera de la UE que dentro. Al fin y al cabo, nadie ha obligado a los británicos a marcharse y no se debe abrir la puerta a que los otros Estados miembros, o incluso los no miembros, puedan solicitar vinculaciones con la UE a la carta"28.

Ahora bien, no habría que minimizar las consecuencias particulares sobre las relaciones bilaterales de cada Estado miembro de la UE en cuanto a sus relaciones con el Reino Unido, que pueden ser muy diferentes. Por citar el caso de España, hay que comprender la interrelación económica ${ }^{29}$ y financiera $^{30}$ entre los dos Estados, así como su grado de interacción en el marco de las exportaciones, el turismo, las infraestructuras, las telecomunicaciones, la energía, etc. sin contar con las particularidades de Gibraltar, de las que no hablaré porque merecen un estudio individualizado.

Como muestra, un botón. Banco de Santander y Banco de Sabadell obtienen el $20 \%$ y el 10\% de sus recursos, respectivamente de su implantación en el Reino Unido, teniendo derechos de créditos por valor del 30\% del PIB español $^{31}$. Y esto es sólo una muestra, porque hay iguales ejemplos en el turismo, la automoción y otros sectores económicos.

Reino Unido es el primer Estado emisor de turistas para España (21,6 \% del total de ingresos turísticos recibidos). En 2019 entraron en España más de 18,08 millones de británicos ${ }^{32}$.

28 Llaudes, Salvador, Molina, Ignacio, Otero Iglesias, Miguel y Steinberg, Federico, "España ante el Brexit", Elcano Policy Paper, Real Instituto Elcano, Madrid, Marzo 2018, pág. 18 (http:// www.realinstitutoelcano.org/wps/wcm/connect/79b903f5-a511-47d8-bbfe-1d99ad75ea80/PolicyPaper-2018-Espana-ante-Brexit.pdf?MOD=AJPERES\&CACHEID=79b903f5-a511-47d8-bbfe1d99ad75ea80).

${ }^{29}$ Matías Batalla, David de, "España y Reino Unido, Dos Economías Avocadas a Entenderse tras el Brexit", en Boletín Económico de ICE, July 2018.

${ }^{30}$ Tapia Hermida, Alberto Javier, "El impacto del Brexit en los mercados financieros durante la tercera fase de la retirada del Reino Unido", en La Ley Unión Europea, n 79, 2020.

${ }^{31}$ Analistas Financieros Internacionales, Brexit: comienza la cuenta atrás, AFI, Madrid, mayo, 2017.

32 A título tan solo informativo, véase El Periódico del 27 de julio de 2020 (https://www.elperiodico. com/es/economia/20200727/tercio-britanicos-eligen-espana-vacaciones-8055757).

Araucaria. Revista Iberoamericana de Filosofia, Política, Humanidades y Relaciones Internacionales, año $22, \mathrm{n}^{\circ} 45$. Tercer cuatrimestre de 2020. Pp. 549-573. ISSN 1575-6823 e-ISSN 2340-2199 https://dx.doi.org/10.12795/araucaria.2020.i45.23 
En España hay casi 250.000 británicos residentes permanentes, según datos del Instituto Nacional de Estadística ${ }^{33}$ y puede que cerca de un millón de residentes temporales, que por su naturaleza no están censados. En el Reino Unido hay unos 200.000 españoles $^{34}$.

Pero a estas cifras oficiales hay que añadir otras más. Durante 2015, por ejemplo, sólo en Andalucía se asistió a 120.730 pacientes extranjeros desplazados temporalmente de los que el $48 \%$ procedía de Reino Unido. Durante 2016 se dedicaron más de diez millones de euros para atender desde el punto de vista sanitario al colectivo británico ${ }^{35}$.

Con los británicos que cotizan y trabajan o viven en España por razones de estudio, turismo, etc., no se generarán problemas, dados que tendrán las mismas prestaciones sanitarias que los españoles en el Reino Unido (Moncloa dixit $)^{36}$. El problema se generará con los residentes pasivos, sean jubilados o dependientes o parados o enfermos o pensionistas, para los que las disposiciones concretas del Acuerdo de Salida deben contemplar estas contingencias.

Los derechos políticos de participación serían un problema menor, porque existen tratados internacionales que los refuerzan ${ }^{37}$.

La UE y todos los Estados miembros, incluida España, han tenido que venir estableciendo acuerdos bilaterales y normas internas para resolver distintas cuestiones incluyendo el problema de los residentes británicos en España, en reciprocidad de la resolución de los problemas de los residentes españoles en el Reino Unido.

Una vez comprobado el rechazo inicial del Parlamento británico al Acuerdo de Salida del Reino Unido, España estableció el Real Decreto 5/2019, de 1 de marzo, por el que se adoptan medidas de contingencia ante la retirada del Reino Unido de Gran Bretaña e Irlanda del Norte de la Unión Europea ${ }^{38}$. Estas medidas tienen que ver con numerosas cuestiones, como las relacionadas con la ciudadanía, la cooperación policial y judicial, las actividades económicas y el transporte.

\footnotetext{
${ }^{33}$ INE, 2019 (https://www.ine.es/prensa/pad_2019_p.pdf).

${ }^{34}$ De la Osa Fondón, Adela, "Posibles efectos tributarios del Brexit", en Anuario del Centro de la UNED de Calatayud, $\mathrm{n}^{\circ}$ 23, 2017, pp. 91-107, especialmente p. 100.

${ }^{35}$ Incorporar una nueva cita a pie de página (nueva 35 ) donde se ponga: Estos datos, aun siendo expresados por la Junta de Andalucía, han sido confirmados tan solo mediante una noticia periodística, que no he podido constratar: "El Confidencial", 4 de julio de 2016 (https://www.elconfidencial.com/ espana/andalucia/2016-07-04/andalucia-diaz-brexit-sanidad-gratuita_1227832/).

${ }^{36} \mathrm{https}$ ://www.lamoncloa.gob.es/brexit/preparacion2/Paginas/271218_seguridadsocial.aspx

${ }^{37}$ Aplicación provisional del Acuerdo entre el Reino de España y el Reino Unido de Gran Bretaña e Irlanda del Norte sobre la participación en determinadas elecciones de nacionales de cada país residentes en el territorio del otro, hecho en Madrid el 21 de enero de 2019 (BOE n ${ }^{\circ}$ 41, de 16 de febrero de 2019, pp. 15231-15234. El definitivo está en estos momentos pendiente de su aprobación por Las Cortes que el pasado 28 de septiembre de 2020 se publicaba en el Boletín oficial de Las Cortes algunas propuestas de enmienda (http://www.congreso.es/public_oficiales/L14/CONG/BOCG/C/ BOCG-14-C-26-2.PDF).

38 Este Real Decreto se hace en el marco de la Directiva 2004/38/CE del Parlamento Europeo y del Consejo, de 29 de abril de 2004. Se publicó en el BOE n 53, de 2 de marzo de 2019 y fue convalidado por el Congreso de los Diputados el 3 de abril de 2019 (BOE nº 86, de 10 de abril de 2019).
} 
En este marco jurídico, el BOE del día 26 de marzo de 2019 ya publicó la Resolución de 25 de marzo de 2019, de la Secretaría de Estado de Migraciones, por la que se publica el Acuerdo del Consejo de Ministros de 22 de marzo de 2019 , en virtud del cual se aprueban las instrucciones por las que se determina el procedimiento, en caso de retirada del Reino Unido de Gran Bretaña e Irlanda del Norte de la Unión Europea sin que se haya alcanzado el acuerdo previsto en el artículo 50 del Tratado de la Unión Europea, para la documentación de los nacionales del Reino Unido residentes en España antes de la fecha de retirada y de los miembros de su familia, así como para la documentación de los nacionales del Reino Unido que reúnan la condición de trabajadores fronterizos antes de la fecha de retirada ${ }^{39}$.

Hay que tener en cuenta que todas estas normas nacionales se hacen a condición de reciprocidad, incluidos los aspectos relacionados con la permanencia, la asistencia sanitaria y las prestaciones sociales, la legalización de sus títulos de formación, la exportación de las pensiones contributivas, etc., por lo que en caso de que el Reino Unido no establezca las mismas normas el Consejo de Ministros podría suspender estos derechos.

Esto es algo inaudito y muy difícil de explicar a un jurista, porque ¿cómo se puede establecer la aplicación de una norma a condición de reciprocidad de otro Estado?

Se excluye que, una vez fuera de la UE el Reino Unido, los ciudadanos británicos puedan acceder a la función pública como funcionarios (sí como empleados laborales).

La propia Unión Europea está estableciendo normas de todos los niveles para minimizar al máximo las consecuencias. Por ejemplo, para regular el transporte, se ha establecido un Reglamento (UE) 2019/502 del Parlamento Europeo y del Consejo, de 25 de marzo de 2019, por el que se dictan normas comunes para garantizar las conexiones aéreas básicas tras la retirada del Reino Unido de Gran Bretaña e Irlanda del Norte de la Unión ${ }^{40}$. Asimismo, un Reglamento (UE) 2019/503 del Parlamento Europeo y del Consejo, de 25 de marzo de 2019, sobre determinados aspectos de la seguridad y conectividad ferroviarias tras la retirada del Reino Unido de la Unión ${ }^{41}$. Igualmente, un Reglamento (UE) 2019/501 del Parlamento Europeo y del Consejo, de 25 de marzo de 2019, por el que se establecen normas comunes para garantizar las conexiones básicas de transporte de mercancías y de viajeros por carretera en relación con la retirada del Reino Unido de Gran Bretaña e Irlanda del Norte de la Unión ${ }^{42}$.

\footnotetext{
${ }^{39} \mathrm{BOE} \mathrm{n}^{\mathrm{o}} 73$, de 26 de marzo de 2019, pp. 30527 y ss.

${ }^{40}$ DOUE(L) no 85 de 27/03/2019, pp. 1049 a 1059.

${ }^{41}$ DOUE(L) no 85 de 27/03/2019, pp. 1060 a 1065.

${ }^{42}$ DOUE(L) no 85 de 27/03/2019, pp. 1039 a 1048.
} 
También se ha establecido un Reglamento (UE) 2019/500 del Parlamento Europeo y del Consejo, de 25 de marzo de 2019, por el que se dictan medidas de contingencia en el ámbito de la coordinación de la seguridad social a raíz de la retirada del Reino Unido de la Unión ${ }^{43}$. O un Reglamento (UE) 2019/499 del Parlamento Europeo y del Consejo, de 25 de marzo de 2019, por el que se establecen disposiciones para la continuación de las actividades de movilidad por motivos de aprendizaje actualmente en curso en el marco del programa Erasmus+ establecido por el Reglamento (UE) n ${ }^{\circ} 1288 / 2013$, en el contexto de la retirada del Reino Unido de la Unión ${ }^{44}$. Y un larguísimo etc. que termina con la publicación, en el día en que estoy revisando estas páginas, con el Reglamento (UE) 2020/1530 del Parlamento Europeo y del Consejo de 21 de octubre de 2020 por el que se modifica la Directiva (UE) 2016/798 en lo que respecta a la aplicación de las normas de seguridad e interoperabilidad ferroviarias en la conexión fija a través del canal de la Mancha, para dar seguridad a la conexión entre Francia y el Reino Unido tras el Brexit ${ }^{45}$.

\section{EI control migratorio, uno de los temas que más preocupa al Reino Unido}

Si analizamos los problemas que han llevado a que los políticos británicos propusieran una salida del Reino Unido de la $\mathrm{UE}^{46}$, el que ha sido mayormente analizado, aunque no todos los analistas lo consideran síi $^{47}$, ha sido el problema migratorio, que no es el problema de la arribada de pateras o cayucos, o de miles de sirios, afganos, sudaneses, etc. que se empantanaron en Grecia o Turquía. No, no era ese el problema migratorio que les preocupaba a los ciudadanos que, de buena fe, se han dejado engañar por los políticos más mediocres de la historia del Reino Unido.

Su preocupación era con los ciudadanos europeos que ocupan puestos de trabajo ( $y$, algunos también, no hay que negarlo, reciben subvenciones por estar en grupos de riesgo). Esos puestos de trabajo son aquellos que no tienen candidatos formados entre los propios ciudadanos del Reino Unido, como la medicina, la hostelería o los servicios domésticos, incluidos los de la dependencia.

Tras la incorporación a la UE de los llamados países del Este (Polonia, República

${ }^{43}$ DOUE(L) no 85 de 27/03/2019, pp. 1035 a 1038.

${ }_{44}$ DOUE(L) no 85 de 27/03/2019, pp. 1032 a 1034.

${ }^{45}$ DOUE(L) no 352 de 22/10/2020, pp. 1 a 3.

46 Álvarez, María Victoria, "La salida del Reino Unido de la Unión Europea: sus causas estructurales", en revista Integración y Cooperación Internacional, nº 23, 2016, pp. 27-31.

${ }^{47}$ Por ejemplo, Navarro, Vinceç, "Lo que los medios no dicen sobre las causas del Brexit", en Público, 25 de junio de 2016, pp. 1-11, especialmente 10 y 11. (http://www.vnavarro.org/wp-content/ uploads/2016/06/Lo-que-los-medios-no-dicen-sobre-las-causas-del-Brexit.pdf). 
Checa, Eslovenia, Lituania, Estonia, Letonia, Eslovaquia y Hungría), casi treinta mil ciudadanos de estos países llegaron al Reino Unido en tan solo dos años ${ }^{48}$.

Ahora bien, la libre circulación de ciudadanos europeos es una de las claves de la UE, política irrenunciable que supone una línea roja para las negociaciones. Una vez aceptado el hecho jurídico del Brexit, al Reino Unido no le queda más remedio que negociar con la UE en el marco de la política migratoria al haberse convertido en un país tercero.

El Tratado de Lisboa considera la política migratoria como una política compartida por la Unión Europea y sus Estados Miembros, llamándola genéricamente política común de control de fronteras, asilo e inmigración. Sin embargo, política común no significa política uniforme.

En ese mismo Tratado de Lisboa se permiten regímenes que puedan excluir compromisos en estas materias, como los de Dinamarca, Reino Unido o Irlanda, que puedan concurrir con otros regímenes (Suecia y Noruega) o incluyentes de otros socios no comunitarios (Suiza o Liechtenstein).

Esta variedad ha permitido la existencia de una red normativa compleja que ahora requerirá ajustes muy importantes porque el Reino Unido tiene que incluir como inmigrantes a los ciudadanos europeos y la UE tiene que incluir a los ciudadanos británicos como inmigrantes de país tercero.

Por ello se hace especialmente importante negociar una fórmula de relación futura. De esta forma, si la UE y el RU decidieran mantener Acuerdos particulares para migraciones controladas o si no hubiera acuerdos y los flujos migratorios entre el RU y la UE y viceversa se sometieran a las normas generales del control de las fronteras, debe ser objeto de negociación profunda.

En el marco negociador actual se hace especial hincapié en el alcance ratione personae, es decir, en el alcance personal; y la base de principios determinada por la UE en su estrategia es que se han de tener en cuenta los intereses de las personas que residan o hayan residido en la fecha de la entrada en vigor del Brexit, los miembros de sus familias cubiertos por la Directiva 2004/38 que estén disfrutando o vayan a disfrutar después del Brexit ${ }^{49}$, los trabajadores fronterizos, etc..

En relación con los ciudadanos de la UE27 y los nacionales del Reino Unido y sus familiares cubiertos por el Reglamento 883/2004 sobre la coordinación de los sistemas de seguridad social, la regla sería que si abandonan o han abandonado el RU o la UE en la fecha de entrada en vigor del Brexit, se conserven sus períodos agregados para el cálculo de beneficios futuros que reemplacen los beneficios (vejez, prestaciones de enfermedad, prestaciones

${ }^{48}$ Salt, John and Millar, Jane, "Foreign labour in the United Kingdom". Labour Market Trends, October, Office for National Statistics, 2006, pp. 335-355.

49 Directiva 2004/38/CE del Parlamento Europeo y del Consejo de 29 de abril de 2004, relativa al derecho de los ciudadanos de la Unión y de los miembros de sus familias a circular y residir libremente en el territorio de los Estados miembros (DOUE L158, de 30 de abril de 2004). 
de invalidez, prestaciones de supervivencia y prestaciones en accidentes de trabajo y enfermedades profesionales), o, incluso, que los pensionistas que hayan abandonado el Reino Unido o UE27 en la fecha de entrada en vigor del Brexit que actualmente se encuentran disfrutando de la exportación de ingresos que sustituyen a los beneficios puedan mantener sus derechos ${ }^{50}$.

En cuanto al ámbito ratione materiae, éste debe alcanzar:

A) Los arts. 18 (igualdad de trato de los estudiantes), 21 (la libre circulación de ciudadanos], 45 ("trabajadores", tal como los define el TJUE, el 48 [seguridad social] y 49 del TFUE ("Autónomos", tal como los define el TJUE);

B) La Directiva 2004/38 (sobre trabajadores y solicitantes de empleo, trabajadores autónomos, estudiantes, económicamente inactivos) que no deben ser discriminados en cuanto a la entrada, residencia, reagrupación familiar, protección contra la expulsión.

C) El Reglamento 492/2011 (trabajadores y solicitantes de empleo - no discriminación, acceso a la mano de obra Mercado para ejercer una actividad, y la no discriminación en las condiciones de trabajo, sociales y fiscales, el acceso de los trabajadores y familiares a la educación, aprendizaje y formación profesional, vivienda, derechos colectivos);

D) El Reglamento 883/2004 y el Reglamento de aplicación 987/2009 (por ejemplo, los principios de coordinación y cooperación entre las autoridades nacionales para el reembolso por el Estado miembro competente de la asistencia sanitaria planificada y no planificada). En este sentido:

Habrá sólo una legislación aplicable, por lo que sólo pagará contribuciones un único Estado. La decisión sobre qué Estado debe ser el pagador se hará de conformidad con el Reglamento (CE) no 883/20.

Se agregarán los períodos anteriores de seguros, trabajo o residencia en otros Estados.

Se exportarán los beneficios, por ejemplo, las pensiones de vejez.

Se exportarán las prestaciones familiares y de desempleo.

E) Se mantendrá el reconocimiento de las cualificaciones profesionales (diplomas, certificados, etc.) obtenidos en cualquier Estado Miembro, así como los obtenidos en cualquier otro Estado que esté reconocido por cualquier otro Estado Miembro de la UE.

F) Mantenimiento del derecho de residencia de los familiares del titular del derecho, aun en caso de fallecimiento, divorcio, etc. de acuerdo con la Directiva 2004/38.

El TJUE mantendría plena jurisdicción en caso de discrepancia en la aplicación de estas normas.

${ }^{50}$ https://ec.europa.eu/commission/sites/beta-political/files/essential-principles-citizens-rights_en_0.pdf 
Ahora bien, esta es la posición de la UE. Habrá que esperar a conocer la posición del RU al respecto que, a fecha de redactar estas páginas aún no se ha pronunciado.

¿Se podrían regular los futuros flujos migratorios entre el RU y la UE mediante acuerdos privilegiados?

La casuística de la Unión Europea en el marco de los acuerdos migratorios con terceros Estados es muy variada. Los de mayor amplitud y a su vez lo más sencillos se han producido con Estados como Islandia, Noruega ${ }^{51}$, Liechtenstein $^{52}$ y Suiza ${ }^{53}$ que han permitido una incorporación plena al sistema de libre circulación de personas, como si sus ciudadanos fueran ciudadanos europeos, con algunas diferencias. Sin embargo, esto no es lo que quiere el Reino Unido porque esto supondría lo que rechaza, no poder controlar el acceso de los ciudadanos europeos al Reino Unido.

El otro marco utilizado por la UE con terceros Estados ha sido el acuerdo de asociación, como el llevado a cabo con Turquía y con otros Estados del Este de Europa, muchos ya Miembros de la UE y del Mediterráneo sur, o los llamados Estados $\mathrm{ACP}^{54}$.

Ahora bien, este tipo de acuerdos particulares para migraciones controladas lo que en realidad suponen es la regulación de las condiciones laborales y sociales para los inmigrantes ya establecidos en la Unión, pero no para nuevos inmigrantes o para los autónomos o prestatarios de servicios, por tiempo limitado y que son de interés para la propia UE.

\section{Los desafíos del futuro inmediato necesitan compañía, no soledad}

Cuando se habla del futuro de Europa resulta recurrente pensar en las reformas necesarias de las instituciones de la Unión Europea para afrontar los nuevos retos a los que tenemos que dar respuestas. Eso, en sí mismo, es un desafío colosal porque aunar voluntades de 27 Estados, cada uno con una historia propia, instituciones diferentes y culturas e intereses político-jurídicos de diversa índole, no son aquellos desafíos a los que me quiero referir.

Europa es algo más que la mismísima Unión Europea, tal como hoy día la concebimos. No se trata de pensar que Europa es geográficamente más extensa que la propia Unión Europea porque, tras la última ampliación de 2013, para

\footnotetext{
51 Cullen, Peter, "The Schengen Agreement with Iceland and Norway: Its main features", ERA Forum 2, 71-75 (2001). https://doi.org/10.1007/BF02817538.

52 Acuerdo de 28 de febrero de 2008. Véase la noticia de la firma en https://ec.europa.eu/ commission/presscorner/detail/en/IP_11_1566.

${ }_{53}$ Boesch-Kohler, Nathalie, "La participación de Suiza en los Acuerdos de la Unión Europea de Schengen, Dublín, Frontex y Europol”, en Foro, Nueva Época, vol. 18, nº 2 (2015), pp. 233-247.

${ }^{54}$ Thym, Daniel \& Zoeteweij Turhan, Margarite (Eds.), Riglts of Third-Country Nationals under EU Association Agreements, Nihjoff, The Netherlands, 2015.
} 
incorporar a Croacia, la Unión Europea coincidirá básicamente con la geografía política de Europa, dado que Rusia tiene y tendrá un proyecto propio, diferente del de la Unión Europea ${ }^{55}$, sin despreciar la necesaria relación entre ambas potencias $^{56}$.

Sin embargo, ahora el Reino Unido queda fuera del flanco occidental continental, que, además, aun habiendo sido una potencia mundial, en solitario será incapaz de liderar ninguno de los imponentes desafíos a los que nos enfrentamos en el mundo contemporáneo y que su posición merma la acción global de la UE en un mundo tan diferente del conocido hasta ahora y con gravísimos nuevos riesgos y amenazas.

Cuando digo que Europa es algo más es porque el proyecto de la Unión Europea debe ser algo más que reformas institucionales o que reparto de votos o cuotas, aun siendo estos elementos de vital importancia también.

La Unión Europea, tan sólo con su política comercial común, es capaz de asegurar una política exterior donde el que quiera comerciar con la Unión Europea (todos quieren) debe cumplir con las estrictas condiciones impuestas en cuanto a calidad, a seguridad, etc. Ya eso, en sí mismo, supone una importantísima herramienta que no cuesta un solo euro.

Respecto al plano externo, donde más nos necesitamos los británicos y el resto de europeos, debemos abordar algo casi imposible con el Reino Unido dentro para que el futuro de Europa tenga credibilidad: la armonización de la política exterior y la autonomía en materia de seguridad y defensa común. Estas dos cuestiones son vitales (los británicos deberían haberlo comprendido) y, quizás, el Brexit pueda suponer una oportunidad para ello ${ }^{57}$.

En materia de política exterior comprendo las distintas sensibilidades que ofrece y, por tanto, comprendo las dificultades a las que la propia Unión Europea se enfrenta. Es verdad que Estados tan diferentes en cuanto a política exterior se refiere necesitan plantear la política exterior europea desde sus propias posiciones. Empero, es hora ya de establecer mecanismos de decisión y de control que no se sustraigan a la estrategia general que pueda marcar el futuro de la UE, aunque sea sin el Reino Unido, el objetor persistente ${ }^{58}$.

Hay quienes piensan que la UE debería reducir sus pretensiones y

55 Sánchez Ortega, Antonio, "La Política Exterior Rusa y su Relación con Occidente. Una Visión desde el realismo Neoclásico", en Revista Española de Derecho Internacional, vol. 72, n 1, 2020, pp. 163-186.

${ }^{56}$ López Jiménez, José Ángel, "La Gestión de la Relación de la Unión Europea con Rusia: un Reto Estratégico Clave", en Moure Peñín, Leire, Cornago Prieto, Noè \& Castro, José Luis (Eds.), Repensar la Unión Europea: Gobernanza, Seguridad, Mercado Interior y Ciudadanía, Tirant Lo Blanch, Valencia, 2019, pp. 697-708.

${ }^{57}$ Dezcallar, Jorge, "El Brexit, una Oportunidad para Europa", en Politica Exterior, nº 176, 2017, pp. 1 y ss.

${ }^{58}$ Guinea Bonillo, Julio, "El Proceso de Consolidación del Euroexcepticismo Británico y el Triunfo del Brexit: Fuerzas Centrípetas para el Reforzamiento de la Política Exterior y la Política de Defensa en la Unión Europea”, en Cadernos de Dereito Actual, nº 9, 2018, pp. 305-331. 
limitarse al contexto europeo y a una especialización sectorial ${ }^{59}$. Sin embargo, eso es poco creíble para la primera potencia comercial del mundo y la primera potencia en valores humanos y cívicos, de los que tan necesitado está el mundo.

Estoy de acuerdo en que "es cierto, históricamente, que Europa ha nutrido de gran parte de los principios e ideas hoy globalmente aceptados como acervo común. Esto, no obstante, no representa ningún 'capital' de poder, ya que esos ideales han sido amortizados y asumidos globalmente"

La UE, cuando incluía al Reino Unido, había adolecido de liderazgo global y se concentraba en las relaciones clásicas que interesaban al Reino Unido y otras potencias internacionales de la UE. Son muy importantes las relaciones económicas, comerciales y de seguridad. Sin embargo, sin el Reino Unido se puede pensar un poco más allá y ver el mundo y el papel de la UE de otra manera, afrontando los nuevos problemas y las nuevas relaciones internacionales. El Reino Unido en solitario, no podrá hacerlo.

Hay problemas globales importantísimos como los nuevos movimientos migratorios, los desplazamientos geoestratégicos derivados de las nuevas fuerzas emergentes de Asia, de los desplazamientos medioambientales, del cambio climático, del control de la energía, de la mundialización del comercio electrónico, de los nuevos aprovechamientos del mar, de la precariedad de las viejas reglas para afrontar los nuevos desafíos ${ }^{61}$. Y la individualidad de los Estados no permite cambios estratégicos para dar soluciones globales. Reino Unido no podrá, pero la UE, tomando el toro por los cuernos, podría hacerlo. Frente a la pujanza de Estados terceros, hasta ahora irrelevantes, y de actores impensables hasta hace poco, se necesita repensar las estrategias de la UE, aunque sea sin el Reino Unido.

Para ello se debe abordar un procedimiento en la toma de decisiones que sea coherente con todo el procedimiento de la UE y establecer unos mecanismos de control que permitan a los distintos Estados y a los ciudadanos en general reclamar su cumplimiento.

Soy consciente de las dificultades de abordar este tema, pero soy más consciente de las que acarrearía no abordarlas. Se haría necesario diseñar, junto a los principios y orientaciones generales de la Política Exterior Común de la Unión Europea y las estrategias comunes, un procedimiento por el que la toma de decisiones en las acciones y posiciones comunes tenga un marcado carácter

\footnotetext{
${ }^{59}$ Closa, Carlos, "La Unión Europea: un Actor Global en un Mundo en Cambio", en Mallo, Tomás \& Sanahuja, José Antonio (Coords.), Las Relaciones de la Unión Europea con América Latina y el Caribe, Fundación Carolina y Siglo XXI, Madrid, 2011, pp. 2 y 3.

${ }^{60}$ Ibidem, p. 11.

${ }^{61}$ Véase AA.VV. "Riesgos y Amenazas para la Seguridad Humana" (monográfico), en Araucaria. Revista Iberoamericana de Filosofía, Política, Humanidades y RRII, año 18, nº 36, 2016, pp. 211-464.
} 
“comunitario". Ya no está el Reino Unido para impedir estas cuestiones.

$\mathrm{Y}$ para servir a dichas acciones y posiciones comunes hay que repensar en el papel de la diplomacia europea que tanto repudiaba el Reino Unido y en la rentabilidad que supondría prescindir de tantos agentes nacionales, con el problema de su multiplicación y la de sus propias funciones. Se impone, pues, el relevo de los agentes diplomáticos y consulares nacionales en favor de un conjunto de agentes de la propia Unión que estén en disposición de llevar a cabo una diplomacia estrictamente europea, sin perjuicio de las particularidades que puedan darse en áreas sensibles para los Estados que conforman la Unión Europea.

Y cuando hablo de política exterior no sólo hablo de economía, de comercio, de geoestrategia, sino que, como he dicho, hablo de cambio climático, de terrorismo internacional, de robots, de biobots, de drones, de big data, de seguridad sanitaria, de seguridad alimentaria, etc. etc. ${ }^{62}$

$\mathrm{Y}$ hay que estar muy atentos a todo lo que está ocurriendo mientras la UE no percibe los riesgos y amenazas que supone la compra estratégica de deuda pública de Grecia, Italia, Irlanda, Portugal o España o la gestión de infraestructuras, como los puertos o las autopistas, por parte de China ${ }^{63}$.

Es verdad que la UE, a veces, da la sensación de parálisis absoluta. Con todo, en los momentos realmente difíciles, pone en marcha programas, herramientas, solidaridades que resultan definitivas para dar respuestas a los graves problemas que amenazan nuestro entorno y el de todo el mundo, que no podemos resolver de forma individualizada y que requieren soluciones compartidas.

Por ejemplo, durante la pandemia de la COVID-19 nos hemos dado cuenta de las necesidades diferenciadas y de las solidaridades necesarias, que sólo pueden abordarse desde un enfoque multilateral. La Unión Europea ha elaborado un plan de refuerzo de los sistemas nacionales de salud y de mitigación del impacto socioeconómico, del que el Reino Unido no se podrá beneficiar.

Está garantizando el suministro de material médico en toda la UE, del que el Reino Unido queda excluido ${ }^{64}$, fomentando la investigación con más de 550 millones de euros para desarrollar tratamientos y vacunas ${ }^{65}$ y elaborando un plan de recuperación que alcanza los 2,3643 billones de euros ${ }^{66}$, de los que el Reino Unido no se podrá beneficiar y que tendrá que elaborar de forma individual, incrementando costos e impidiendo alcanzar objetivos ambiciosos.

Respecto a la seguridad y defensa común, en Europa el futuro pasa por no prejuzgar la labor de la OTAN, que de momento debe seguir siendo prioritaria

${ }^{62}$ Fernández Sánchez, Pablo Antonio, "La necesidad de cambios jurídicos estratégicos para los nuevos escenarios mundiales" en The Global Community - Yearbook of International Law and Jurisprudence 2008, vol. I, 2009, pp. 285-294.

${ }^{63}$ Ibidem, p. 5.

${ }^{64} \mathrm{https}$ //www.consilium.europa.eu/es/policies/coronavirus/covid-19-public-health/

${ }^{65} \mathrm{https}$ //www.consilium.europa.eu/es/policies/coronavirus/covid-19-research/

${ }^{66} \mathrm{https}$ ://www.consilium.europa.eu/es/policies/coronavirus/covid-19-economy/ 
en la gestión de la crisis, por lo que ninguna propuesta debería afectar al Tratado de Washington ${ }^{67}$. Aquí la UE y el Reino Unido van de la mano y debemos ser conscientes de la necesidad de aunar esfuerzos. El propio Gobierno del Reino Unido, una vez consumado el Brexit, ha reiterado formalmente su compromiso con la OTAN y la seguridad europea ${ }^{68}$.

Sin embargo, hay que destinar muchos más recursos a la investigación, más puestas en común de instrumentos militares, más estrategias de seguridad que otorguen autonomía a las decisiones propias para los intereses de todos y eso es más fácil y necesario en el marco interno de la UE. Ahora, con la salida del Reino Unido será todo ello mucho más caro pero mucho más fácil, porque el Reino Unido ha venido siendo un freno para muchas de las acciones e instrumentos de la Unión Europea, como la Agencia Europea de Defensa ${ }^{69}$.

Como reconoce López Garrido, "se dan todas las condiciones para que Alemania, España e Italia entren a sustituir a RU en un grupo de países partners de Francia en esa política tan decisiva para que la Unión se convierta en un 'actor global' en el mundo"70. La Unión Europea podría hacer valer que es el primer pagador de misiones de paz de la ONU ${ }^{71}$, incluso sin el Reino Unido, que quedaría relegado a la insignificancia, y la contribución de la Unión Europea a los organismos humanitarios, siendo el primer donante de ayuda, con diferencia del segundo y los demás, dejará al Reino Unido con una contribución residual que no podrá invocar en la toma de decisiones.

El Reino Unido seguirá con el derecho de permanencia permanente en el Consejo de Seguridad, el tiempo que le permitan los demás actores globales, pero, ahora más que nunca, la UE podrá reclamar un sillón propio para sí misma, restando influencia británica en las tomas de decisiones.

\footnotetext{
${ }^{67} \mathrm{https}$ //eeas.europa.eu/sites/eeas/files/implementation_plan_on_security_and_defence_02-03-2018.pdf

${ }^{68} \mathrm{https}$ ://www.gov.uk/government/news/uk-further-commits-to-nato-and-european-securitythrough-jef-readiness-declaration-and-deployment-of-typhoons-to-lithuania

${ }^{69}$ De hecho, los propios británicos creen que el Brexit pueda promover el ímpetu para una mayor integración en el campo de la defensa europea. Véase, Black, James, Hall, Alexandra, Cox, Kate, Kepe, Marta \& Silfversten, Erik, Defence and security after Brexit Understanding the possible implications of the UK's decision to leave the EU - Overview Report, RAND Corporation, Santa Monica, CA (USA), 2017, p. 12. (https:/www.rand.org/pubs/research_reports/RR1786z1.html).

${ }^{70}$ López Garrido, Diego \& Ruiz Campillo, Xira, "La defensa europea después del Brexit", en OPEX, Doc. de Trabajo n ${ }^{\circ} 87 / 2017$, p. 40.

71 Galán Pardo, Pablo, "La Financiación de las Operaciones de Mantenimiento de la Paz por parte de las Organizaciones Internacionales - Los casos de Naciones Unidas, OTAN y UE”, en Revista Electrónica de Estudios Internacionales, no 30, 2015, DOI: 10.17103/reei.30.14 (http://www.reei.org/ index.php/revista/num30/notas/financiacion-operaciones-mantenimiento-paz-parte-organizacionesinternacionales-casos-naciones-unidas-otan-ue).
} 


\section{Conclusiones}

El Reino Unido ha necesitado siempre a la Unión Europea tanto o más que la Unión Europea al Reino Unido, pero casi nunca ha sido leal a la misma. Desde que comenzó su andadura, la Unión Europea ha venido sufriendo las exigencias británicas y, sobre todo, la falta de voluntad de integración que requiere nuestro continente para su supervivencia como actor global.

Europa no puede ni debe permitirse ser irrelevante en la gobernanza del mundo, porque quedaríamos relegados a ser una potencia regional menor, sectorizada y empobrecida, sin capacidad de influencia.

En lo positivo y lo negativo el mundo sigue siendo eurocéntrico a pesar de todo, a pesar de que sus valores exportados ya forman parte de los valores comunes y esto, en sí mismo, no suponga un valor añadido de "poder".

La Unión Europea se ha visto beneficiada por una política comercial cuya intencionalidad no era la consecución de un mundo rendido a sus pies. Son miles de exigencias las que requiere la Unión Europea en sus cientos de tratados comerciales, de inversiones, etc., que le permiten crear un espacio global comercial (no hay que olvidar que la UE seguirá siendo, después del Brexit, la zona de mayor comercio del mundo). Si para vender productos a la UE, aunque sea a China, se requieren condiciones, reglas estrictas de protección de la calidad, del consumo, de la sostenibilidad de los materiales, etc. etc., tan sólo eso, en sí mismo, ya es un arma potentísima de liderazgo.

Igualmente, en el marco de la investigación. Es verdad que el Reino Unido ha sido un imponente motor de la investigación europea, pero no hay que olvidar que no es por su especial talento investigador, sino por las multimillonarias aportaciones de los programas europeos, especialmente H2020 y otros muchos, que ahora mermarán sobremanera su potencial investigador. Las universidades británicas estarán muy preocupadas por la reducción de tan importantes aportaciones europeas.

Quizás también sufra, incluso, el idioma, que debe dejar de ser oficial (aunque siga siendo de trabajo), puesto que ni Irlanda (gaélico), ni Malta (maltés) lo eligieron como lengua oficial. Será muy difícil y lento desplazar la comunicación oficial en inglés, la lengua más hablada en Europa y la más extendida en el mundo de los negocios internacionales, pero será paulatinamente inexorable su depreciación en el marco de la Unión Europea.

El Reino Unido, una vez más, ha optado por una de sus naturalezas bifrontes, la de lobo estepario, que le condena a una existencia perturbada. 


\section{Referencias bibliográficas:}

Adler-Nissen, Rebecca, Opting Out of the European Union, Diplomacy, Sovereignty and European Integration, Cambridge University Press, Cambrigde, UK, 2014.

Alonso Seco, José María, Política Social Europea, UNED, Madrid, 2014.

Álvarez, María Victoria, "La salida del Reino Unido de la Unión Europea: sus causas estructurales", en Revista Integración y Cooperación Internacional, $\mathrm{n}^{\circ} 23,2016$, pp. 27-31.

Analistas Financieros Internacionales, Brexit: comienza la cuenta atrás, AFI, Madrid, mayo, 2017.

AA.VV., "Riesgos y Amenazas para la Seguridad Humana" (monográfico), en Araucaria, año 18, n 36, 2016, pp. 211-464.

Bailes, Alyson JK \& Messervy-Whiting, Graham, Death of An Institution - The end for the Western European Union, a Future for European Defense?, Egmont, Brussels, Belgium, 2011.

Bar Cendón, Antonio, "El Reino Unido y la Unión Europea: Inicio y Fin de una Relación Atormentada", en Teoría y Realidad Constitucional, n $4^{\circ}, 2017$, p. 141-180.

Baur, George, Sánchez Rydelski, Michael \& Zatschler, Carsten, European Free Trade Association (EFTA) and the European Economic Area (EEA), second edition, Kluwer Law International, BV, The Netherlands, 2018.

Beale, Kieron, "The United Kingdom without the Charter of Fundamental Rights of the European Union: Putting Down the Dog that thid not Bark", en Birkinshaw, Patrick J. \& Biondi, Andrea (Eds.), Brtain Alone! - The implications and Consequences of United Kingdom Exit from the EU, Walter Kluwer, The Netherlands, 2018.

Black, James, Hall, Alexandra, Cox, Kate, Kepe, Marta \& Silfversten, Erik, Defence and security after Brexit Understanding the possible implications of the UK's decision to leave the EU - Overview Report, RAND Corporation, Santa Monica, CA (USA), 2017. (https://www.rand.org/ pubs/research_reports/RR1786z1.html).

Boesch-Kohler, Nathalie, "La participación de Suiza en los Acuerdos de la Unión Europea de Schengen, Dublín, Frontex y Europol”, en Foro, Nueva Época, vol. 18, nº 2 (2015), pp. 233-247.

Brown, Stuart A., "Brexit, the UK and Europe: Why, how and what next?", en Journal of European Integration, 41:1, 2019, pp.123-129.

Calvo Hornero, Antonia, Organización Monetaria y Financiera de la Unión Europea, segunda edición, Editorial Universitaria Ramón Areces, UNED, Madrid, 2019. 
Cervera Valterra, María, "La Disolución de la Comunidad Europea del Carbón y del Acero: Estado Actual", en Revista de Derecho Comunitario Europeo, 6 (12), 2002, pp. 393-432.

Closa, Carlos, "La Unión Europea: un Actor Global en un Mundo en Cambio", en Mallo, Tomás \& Sanahuja, José Antonio (Coords.), Las Relaciones de la Unión Europea con América Latina y el Caribe, Fundación Carolina y Siglo XXI, Madrid, 2011, pp. 1-26.

Cullen, Peter, "The schengen agreement with Iceland and Norway: Its main features". ERA Forum 2, 2001, pp. 71-75. https://doi.org/10.1007/ BF02817538.

De Gaulle, Charles, “Conférence de presse de Charles de Gaulle: le second veto (27 novembre 1967)", Centre Virtuel de la Connaissance sur 1'Europe (CVCE), Université du Luxembourg: http://www.cvce.eu.

De Gaulle, Charles, “Conférence de presse du 14 janvier 1963 (sur l'entrée de la Grande-Bretagne dans la CEE)", en De Gaulle, Charles, Paroles Publiques (Institut national de l'audiovisuel, INA, Réf. 00085: http:// fresques.ina.fr/de-gaulle/fiche-media/Gaulle00085/conference-de-pressedu-14-janvier-1963-sur-l-entree-de-la-grande-bretagne-dans-la-cee.html.

De la Osa Fondón, Adela, "Posibles efectos tributarios del Brexit", en Anuario del Centro de la UNED de Calatayud, no 23, 2017, pp. 91-107.

Descallar, Jorge, "El Brexit, una Oportunidad para Europa", en Política Exterior, $\mathrm{n}^{\circ} 176,2017$, pp. 1 y ss.

Emerson, Michael, "Britain, Ireland and Schengen: Time for Smarter Bargain on Visas", en Center for European Policy Studies Policy Briefs, n 249, 2011.

Fernández Sánchez, Pablo Antonio, "La necesidad de cambios jurídicos estratégicos para los nuevos escenarios mundiales" en The Global Community - Yearbook of International Law and Jurisprudence 2008, vol. I, 2009, pp. 285-294

Galán Pardo, Pablo, "La Financiación de las Operaciones de Mantenimiento de la Paz por parte de las Organizaciones Internacionales - Los casos de Naciones Unidas, OTAN y UE", en Revista Electrónica de Estudios Internacionales, $\mathrm{n}^{\mathrm{o}}$ 30, 2015, DOI: 10.17103/reei.30.14 (http://www.reei.org/index.php/ revista/num30/notas/financiacion-operaciones-mantenimiento-paz-parteorganizaciones-internacionales-casos-naciones-unidas-otan-ue).

Guinea Bonillo, Julio, "El Proceso de Consolidación del Euroexcepticismo Británico y el Triunfo del Brexit: Fuerzas Centrípetas para el Reforzamiento de la Política Exterior y la Política de Defensa en la Unión Europea”, en Cadernos de Dereito Actual, no 9, 2018, pp. 305-331. 
Llaudes, Salvador, Molina, Ignacio, Otero Iglesias, Miguel y Steinberg, Federico, "España ante el Brexit", Elcano Policy Paper, Real Instituto Elcano, Madrid, Marzo 2018. (http://www.realinstitutoelcano.org/wps/wcm/ connect/79b903f5-a511-47d8-bbfe-1d99ad75ea80/Policy-Paper-2018Espana-ante-Brexit.pdf?MOD=AJPERES\&CACHEID=79b903f5-a51147d8-bbfe-1d99ad75ea80).

López Escudero, Manuel, "La Unión Económica y Monetaria (I)”, en Ortega

Gómez, Marta (Ed.), Las Políticas de la Unión Europea en el Siglo XXI, Bosch Editor, Barcelona, 2017, pp. 299-338.

López Garrido, Diego \& Ruiz Campillo, Xira, "La Defensa Europea después del Brexit", en OPEX, Doc. de Trabajo nº 87/2017.

López Jiménez, José Ángel, "La Gestión de la Relación de la Unión Europea con Rusia: un Reto Estratégico Clave”, en Moure Peñín, Leire, Cornago Prieto, Noè \& Castro, José Luis (Eds.), Repensar la Unión Europea: Gobernanza, Seguridad, Mercado Interior y Ciudadanía, Tirant Lo Blanch, Valencia, 2019, pp. 697-708.

Matías Batalla, David de, "España y Reino Unido, Dos Economías Avocadas a Entenderse tras el Brexit", en Boletín Económico de ICE, July 2018, pp. 31-52.

Navarro, Vinceç, "Lo que los medios no dicen sobre las causas del Brexit", en Público, 25 de junio de 2016, pp. 1-11. (http://www.vnavarro.org/wpcontent/uploads/2016/06/Lo-que-los-medios-no-dicen-sobre-las-causasdel-Brexit.pdf).

Salt, John and Millar, Jane, "Foreign labour in the United Kingdom", en Labour Market Trends, October, 2006, pp. 335-355.

Sánchez Ortega, Antonio, "La Política Exterior Rusa y su Relación con Occidente. Una Visión desde el realismo Neoclásico”, en Revista Española de Derecho Internacional, vol. 72, nº 1, 2020, pp. 163-186.

Tapia Hermida, Alberto Javier, "El impacto del Brexit en los mercados financieros durante la tercera fase de la retirada del Reino Unido", en $L a$ Ley Unión Europea, no 79, 2020.

Thym, Daniel \& Zoeteweij Turhan, Margarite (Eds.), Riglts of Third-Country Nationals under EU Association Agreements, Nihjoff, The Netherlands, 2015.

Torsten, Stein, "La Sentencia del Tribunal Constitucional Alemán sobre el Tratado de Maastricht", R.I.E., vol 21, no 3, 1994, pp. 745-770. 
